\title{
Working with Journalists: Media Access and Why You May Need It
}

\author{
R. T. Fienberg and S. P. Maran
}

American Astronomical Society, email: rick.feinberg@aas.org

The Washington Charter for Communicating Astronomy with the Public says that "individuals and organizations that conduct astronomical research - especially those receiving public funding for this research - have a responsibility to communicate their results and efforts with the public for the benefit of all." Aside from a sense of obligation, though, there are other reasons why astronomers ought to communicate with the broader citizenry. Among them: it is encouraged by the leaders of government funding agencies, it helps further public recognition and support for science in general and for astronomy in particular, and it can enhance one's career prospects.

One of the most effective ways to reach the public is through the news media. But scientists and reporters don't necessarily agree on what constitutes "news". In practice, news is what reporters want to cover, not necessarily what scientists and institutions want to publicize.

In Science and Journalists - Reporting Science as News (Free Press, 1986), Sharon Friedman writes, "Editors and reporters tend to value stories that contain drama, human interest, relevance, or application to the reader, criteria that don't always map easily onto scientific importance."

If scientific importance doesn't guarantee newsworthiness, what other criteria might apply? In The Hands-On Guide for Science Communicators (Springer, 2007), Lars Lindberg Christensen offers a list that includes such things as relevance (the issue has influence on people's lives or on the way they think about the world), conflict (the discovery involves a hotly debated topic or resolves a hotly contested issue), a record (the discovery is the first, last, oldest, youngest, biggest, smallest), and aesthetics (the finding is accompanied by an exceptionally beautiful image). But in Making the News (Westview, 1998), Jason Salzman offers a list of things that will send reporters running in the other direction. Of particular relevance to science news, that list includes complexity.

Here's a useful way to tell if you have a newsworthy story: In a single paragraph of no more than 75 words, answer the questions Who?, What?, When?, Where?, Why?, How?, and, most importantly, So what?, then show it to a couple of people who aren't astronomers. If they are intrigued, you've got news. If not, you probably don't.

When is the right time to announce new findings? Upon presentation at a conference? Upon submission of a paper? Upon acceptance of a paper? Upon publication of a paper? Each of these options has pros and cons. Worse, scientists don't necessarily have control of the timing, because reporters have ready access to "unreleased" results, such as presentations at meetings, posts to online preprint servers, advance electronic publication of journal papers, talks at university colloquia, and even such informal sources as astronomers' websites, blogs, Facebook pages, and Twitter feeds.

A key question when thinking about announcing something to the news media is whether or not your results are embargoed. Embargoes are used by journals such as Nature and Science to make results available to journalists in advance with the understanding that their news reports will not be published until a specified date and time, 
usually a few days hence. On the plus side, embargoes give reporters time to do their homework before writing their stories, potentially resulting in higher-quality coverage of the science. On the minus side, scientists may refuse to discuss unembargoed results (often because they misunderstand embargo rules), and journalists have a harder time getting a "scoop". Some of the main embargo policies affecting astronomers are:

- http://www.nature.com/nature/authors/policy/embargo.html (Nature)

- http://www.sciencemag.org/site/help/authors/embargo.xhtml (Science)

- http://aas.org/press/embargo_policy (American Astronomical Society)

Who do you call with your news? The New York Times? No, you call your institutional PIO (public-information officer). PIOs are (usually) experienced science writers; they're experts on their "beat" (subject area), they have established relationships with local/regional/national media, and they know how to get institutional approval for press releases and other types of announcements.

Depending on the nature of your project and the makeup of your team, you may need to work with PIOs at your institution, observatories, space missions, funding agencies, and so on. How do you find these people? Media contacts are listed on institutions' websites, under headings such as "media relations", "press", or "news".

Your PIO may choose to get the word out via a press release, via your participation in a press conference (if the result is being presented at a scientific meeting and/or if the result is extraordinary), and/or via personal pitches to individual journalists. In any case, your PIO will probably offer to prepare you to talk with reporters, perhaps even providing media training to enable you to find the right words, relax on camera, and hone your message into appropriate "sound bites".

It's very important not to wait till the last minute to contact your PIO about a forthcoming newsworthy science result, because it typically takes several weeks to write, edit, and illustrate a press release and to get it approved for distribution by all the institutions involved in the announcement.

Press releases used to go only to bona fide journalists (by mail, then by fax, then by email) and were used as the jumping-off point for researching and writing original news articles. Now, with journalists being laid off in alarming numbers and press releases posted online for easy aggregation, often the only "news article" that appears - all over the Internet - is the press release itself. Thus it is vital that the release be well written, error free, and approved by all who have a stake in it.

There are numerous services that distribute press releases to qualified journalists, among them EurekAlert!, AlphaGalileo, and PR Newswire. In astronomy, the most effective way to get your announcement into the hands of reporters, editors, broadcasters, and others worldwide who regularly cover astronomy and space science is to have your PIO send it to the AAS at press-release@aas.org.

For more information, ask your PIO if he or she has any guidelines for preparing press releases and/or participating in press conferences. Ask, too, if your institution offers media training. If it doesn't, you can take advantage of media-training programs offered by scientific societies, funding agencies, and private consultants. Here's a good place to start: http://communicatingscience.aaas.org/Pages/newmain.aspx

Finally, there are many good books available for scientists who want to do a better job of communicating with the public. Two of the best are Am I Making Myself Clear? A Scientist's Guide to Talking to the Public by Cornelia Dean (Harvard, 2009) and The Hands-On Guide for Science Communicators: A Step-by-Step Guide to Public Outreach by Lars Lindberg Christensen (Springer, 2007). 